\title{
The Art of Medical Photography in Breast Surgery: Clinical, Intra-operative and Specimen Photography - Standards and Recommendations
}

\author{
Sertaç Ata Güler ${ }^{1,2^{*}}$, Osman Demir ${ }^{3}$ \\ ${ }^{1}$ Kocaeli University, Faculty of Medicine, General Surgery Department, Breast - Endocrine - Obesity Surgery Unit, \\ Medical Visual Documentation Unit, Kocaeli, Turkey \\ ${ }^{2}$ SENATURK - Turkish Senology Academy, Istanbul, Turkey \\ ${ }^{3}$ Kocaeli University Faculty of Fine Arts, Photography Department, Kocaeli, Turkey
}

${ }^{*}$ Corresponding author: Sertaç Ata Güler, MD

Kocaeli University, Faculty of Medicine General Surgery Department, Kocaeli Turkey

E-mail: drsataguler@icloud.com

\section{Rezumat}

Arta fotografiei medicale în chirurgia sânilor: fotografia clinică, intraoperatorie și a piesei de rezecție - standarde și recomandări

Documentația medicală vizuală este o sursă de informații deosebit de importantă pentru medicină. Fotografia medicală a devenit metoda principală a documentației vizuale medicale. În chirurgia sânilor, ca în toate celelalte ramuri medicale, fotografia medicală are un rol major în educație şi în urmărirea pacientului. Literatura publicată a fost revizuită pentru tehnici de fotografie medicală. În cooperare cu departamentul de fotografie a facultății de arte plastice, au fost analizate şi identificate standardele pentru fotografia clinică, intraoperatorie şi a piesei de rezecție în chirurgia sânilor. Drept urmare, am elaborate o serie de recomandări pentru obținerea unor fotografii medicale de înaltă calitate şi mai eficiente din punct de vedere academic în chirurgia sânilor.

Cuvinte cheie: fotografie medicală, chirurgie a sânilor, documentație vizuală

\section{Abstract}

Medical visual documentation is an especially important source of information for medicine. Medical photography has become the main method of medical visual documentation. In breast surgery, as in all other medical branches, medical photography has a major role in education and patient follow-up. The 
published literature was reviewed for medical photography techniques. In co-operation with the University fine arts faculty photography unit, standards for clinical, intra-operative and specimen photography in breast surgery were analyzed and identified. As a result, we have made recommendations for obtaining high quality and academically more effective medical photographs in breast surgery.

Key words: medical photography, breast surgery, visual documentation

\section{Introduction}

Technological advances and the widespread use of digital imaging techniques have become commonplace in the 21st-century. Medicine has been no stranger to these changes. The development of technology and digital imaging in all its forms has played a major role in medical visual documentation, which is as important today for education, record keeping and patient follow-up. Visual documentation is divided into twobranches. Photography mainly involves still images. Videos are films, clips or other moving images. Medical photography is the main and most widely used branch of medical visual documentation in all areas of medicine (1).

Medical photography has a role to play in areas as diverse as medical education, medical archiving, patient files, forensic medicine, academic publication, scientific presentations, and for illuminating new techniques, including surgery. Pre-operative and post-operative photography can be used to demonstrate functional deficits or improvements and operative results. Medical photography also provides a tool for the evaluation of the surgeon. Intra-operative photography of procedures and specimen photography provide evidence and examples that can prove important for education, communication and medicolegal purposes (1-3).

In 1845 , less than 20 years after the first photograph was taken, the first pre-operative and post-operative photographs in plastic and reconstructive surgery were printed in a medical journal by Gurdon Buck (3). In the past, medical photography was a duty of professional medical photographers working in hospitals. Their profession wasas a photographer. Whenever requested by medical staff, medical photographers would attend the operating theatre or clinic with their cameras and would obtain high-quality images under direction from the doctor. After the advent of digital technology, it became much easier to carry a relatively powerful digital camera and the doctor was able to takeimages without the need for another person or any direction - the medical professional could obtain the specific images they wanted with much less delay. Doctors started to use their cameras and mobile devices equipped with cameras and took their medical photographs themselves. This has given rise to the question of the quality of these images, obtained not by photography professionals but by medical professionals, as these images remain real medical documents (1).

As in other fields of medicine, breast surgery makes use of all types of visual documents. The main aim of this article isto provide guidance for obtaining high-quality and academically effective medical photographs in breast surgery.

\section{Fundamentals of Taking Medical Photographs}

At this point, the question is, if we were taking our medical photographs, what do we need for obtaining high-quality medical photographs? There are three basic steps for taking the best high-quality medical photographs: basic photography knowledge; features of medical subject and object; and medical sensitivities and ethical-legal issues. When these three basic concepts are understood and combined, 
high-quality medical photographs will be the outcome.

\section{Basic photography knowledge}

Photography is mainly writing with light. So, to write with the correct light, exposure control must be the most basic knowledge. In exposure control, your camera's sensitivity to light (known as ISO - International Standards Organization), aperture, and shutter speed are the main parameters of the camera to control the light (1-3).

In addition, the type of camera used for medical photography is another issue. A professional camera with a changeable lens is the correct choice. But mobile phones, often with powerful photographic capabilities, are almost ubiquitous today and it is impossible to exclude mobile phones from our lives. However, for digital photographic devices there is a rule that states that a larger sensor size is the best to permit more light per pixel and because mobile phones have smaller sensors, professional cameras are still preferable (1).

Although we recommend some standards need to be taken into considerations, we should always try to be more inclusive. Meaning that artificial intelligence (AI) devices can nowadays compensate for poor cameras of mobile phones. $\mathrm{AI}$ is intelligence demonstrated by machines, unlike the natural intelligence displayed by humans and animals. Simple mobile phone cameras can now perform advanced digital image enhancements, such as digital zoom, high dynamic range (HDR) merging, and digital refocusing. Almost uniformly across manufacturers, specs have improved so much that it doesn't really matter which brand of hardware youchoose today. You're guaranteed to get a superb quality of photographs eitherway. What is starting to make a tangible difference, however, is the softwareembedded in digital cameras, including those in mobile phone cameras. Now that AI can analyze and enhance photographs, different algorithms can be employed to achieve targeted results. Algorithms that reconstruct depth, refocus, adjust viewpoints, or merge HDR can turn simple digital lenses into complex equipment that not only captures but analyses and interprets inputs to provide sophisticated insights. As neural processing units become more advanced, mobile phone cameras powered by machine learning can enable other applications that we haven't yet thought of, for instance in health and wellness. Shadow detection and correction can be used in surveillance technology, image reconstruction can be achieved for badly damaged or aged documents, automatic facial and body photographic enhancements have proven popular with consumers. Intelligent photo management software is one thing, but $\mathrm{AI}$ and machine learning are arguably having a bigger impact on how images are captured in the first place. Lenses continue to get a little faster and sensors can always get a little bigger, but we're already pushing at the limitations of physics when it comes to cramming optical systems into slim mobile phone devices. Nevertheless, it's not uncommon these days for mobile phones to take better photos in some situations than a lot of dedicated camera gear, at least before postprocessing. All the mobile phones although they have the modern AI technology are still making the images look real and try images to be more beautiful. But we are obtaining real documents in medical photography. So, we need real documents, not the images that are looking real. The professional cameras obtain the images that are more like the real, just as the documents. The two ideas are not the same as to show beautiful like the images of AI mobile phones and to show more near to the real like the images of the professional cameras. AI is always machine related and not always real.

Unlike analogue images, digital images are easy to edit. There are two main types of editing which are of interest. The first one is optimization, meaning to obtain the best viewable image without compromising the original image content. The second type of digital image editing is known as manipulation and can be used to change the original content of the image so that it becomes significantly modified. In medical photography, optimization is needed but manipulation is forbidden because medical photographs are a true record 
of a patient medical history and manipulating a medical photograph can be thought of as being like falsifying a written record of a patient's therapy. Basic optimizationssuch as cropping, color balancing, and exposure compensation can be done to obtain the best quality medical images (1).

Also, image format is another area of basic knowledge. The recommendation is to take the photography in RAW image format, which is an original and, importantly, uncompressed format. You may make appropriate optimizations in RAW image format while retaining the most original digital information. Alternative image formats include JPEG (or JPG - joint photographic experts' group), TIFF (tagged image file) or PNG (portable network graphics) which are then compressed and the most easily used,low-capacity image formats that can be used in medical photography $(1,4)$.

\section{Features of medical subject and object}

When taking high-quality medical photographs, we must obey the rules of the workplace and give appropriate respect to the medical subject and object - this is still a patient/medical professional relationship. Recommendations concerning an appropriate approach to the medical setting when obtaining clinical photographsof medical subject and object are listed in Table 1 (1,5). We also recommend avoiding theuse of extra drawings or types of masking which may hide the recognizable areas of the patient, and instead recommend careful use of image framing when taking photographs.

Table 1. Recommendationsconcerning appropriate behavior when obtaining clinical photographs

Work with a nurse
Make eye contact with the patient
Show the photographs to the patient
Express the real dimensions by using a ruler
Empathy with the patient
Obey the rules of operation room with special consideration for sterility
Focus on the object exclude other distractions
Control the light of the room during photography
Dismiss non-essential features of the patient such as clothes, jewelry,
make-up, hair, and use a flat, non-distracting background

\section{Medical sensitivities and ethical-legal issues}

Medical photography is a document. So, reality must not be hidden or invented. The subject and the object must not be hidden, not be changed, or not ignored. Medical photographs are different from other photographs, for example for art or journalism. They permanently expose the patient's identity (1). Medical photographs record a particular moment in time, even when the disease passes. It should be remembered that the patient will always prefer to remain confidential and images must be anonymized before evaluation.

Due to the nature of photography, the document created requires the development of standard visual and measurement techniques, especially in areas where it is used as source data. So, standardization in medical photography gains major importance. As a descriptive visual, the uniformity of photographs, such as passport photos in identity documents we use for internationally recognized proof of identity are the most ideal photographic form for inventory-qualified images used for scientific purposes. Animage created using a pre-scaled view (standard lens, tripod, controlled distance), control of the color effect created by the light temperature (Kelvin degree or "warmth", white balance settings), and clean background that minimizes the effects of the environment (background curtain) must be a standard to establish the best results in visuals. One of the most important problems for medical photography in order for it to be recognized as scientific data is that there is a lack of standard-setting awareness (standardization), which is often overlooked during the viewing and recording process. No such standards have yet been developed.

Photography education, as an academic art branch, includes information that includes different qualities of photographic images produced for different purposes. When we look at the artistic productions in the history of photography, there was a way of seeing that was developed, especially in the early 1900 s, which is called "straight photography". This way of seeing, which aimed to record the 
function of the object, later formed the concept of typology in photography. Typological photographs do not contain the identity of the person taking the photograph. Photographs are taken with similar distances, similar light conditions, similar equipment, and the results are brought together and displayed. Typological photography, which continues to be applied as an artistic expression method, can be used as the production method of medical photography where scientific data are recorded. The person producing the photograph should act as a mechanical tool - a "robot" - behind the standard vision set. The contribution of the person producing the photograph on the final image is to ensure the optimal use of equipment that will make the photographers choices record the subject in the most, true-tolife and ideal way. Otherwise, an "interpreted" vision will eliminate a qualified presentation of scientific data and reduce the scientific document quality of the resulting visual.

Further important features of medical photography are medical-legal issues. Medical visual documents are real documents and most of them are confidential. The patient should confirm that written consent has been given before photographsare obtained (5). Prepared medical photography patient consent forms, declaring that the photographs are solely for medical purposes and will be securely saved, must be signedboth by the patient and one of the relatives (1).

\section{Medical Photography in Breast Surgery}

As in other fields of medicine, medical photo- graphy has an important role to play in breast surgery. Medical photography can be used to record stages of the disease, specimens, radiological images, wound healing, microscopic findings, aesthetic results after breastconserving surgery, and surgical procedures (before, during and after) in breast surgery (5). Photographic assessment is as effective as a live assessment in post-surgical cosmetic assessment $(5,6)$. Breast surgery photography can be useful during breast reduction, breast reconstruction, breast augmentation, implants, gynecomastia surgery, and oncoplastic surgery.

Breast surgery photography can be divided into three major subgroups: clinical photography, intra-operative photography, and specimen photography. For every subgroup we give recommendations.

\section{Clinical photography}

This is the subgroup of breast surgery photography in which the patient is alive and conscious, not under anesthesia. It is mainly used for pre-operative or post-operative photographs of breast surgery patients or documenting breast diseases.

We recommend using a clinical photography studio. As discussed earlier we also recommend standardization for ratios, viewpoints, background, and light because this will make photographic records comparable, both over time and between patients $(3,4,7)$. All the recommendations in clinical breast photography are divided into high-level facilities and low-level facilities as given in Table 2.

Clinical photography must be performed in a place with a basic studio setting containing

Table 2. Recommendations for clinical breast photography according to high-level facilities and low-level facilities

\begin{tabular}{lll}
\hline & Recommendations for High-Level Facilities & Recommendations for Low-Level Facilities \\
\hline Place & $\begin{array}{l}\text { A room with a painted, plain, dark colored wall without any windows } \\
\text { to obtain the most accurate color tone as studio setting }\end{array}$ & A special area for photography just at the examination room \\
\hline Camera & $\begin{array}{l}\text { A professional camera with a changeable lens and with an exposure } \\
\text { control system }\end{array}$ & A standard camera or a mobile phone \\
\hline Background & $\begin{array}{l}\text { A uniform backdrop which is anti-reflected, solid light to medium blue } \\
\text { or 18\% gray in color for the background }\end{array}$ & $\begin{array}{l}\text { A one-color wall or fabric curtain or surgical towels attached } \\
\text { to the wall }\end{array}$ \\
\hline Light & $\begin{array}{l}\text { Two matched lights at 45 degrees towards the subject, especially para } \\
\text { flashes or led lights and an extra filling light from reflectors }\end{array}$ & Standard room lights just over the object \\
\hline Education & Having medical photography certificates & At least having basic photography knowledge \\
\hline
\end{tabular}


Figure 1. Sample medical photography studio (Kocaeli University Faculty of Medicine, Medical Visual Documentation Unit, Medical Photography Studio, Kocaeli, Turkey)

(From the archives of Sertaç Ata Güler)

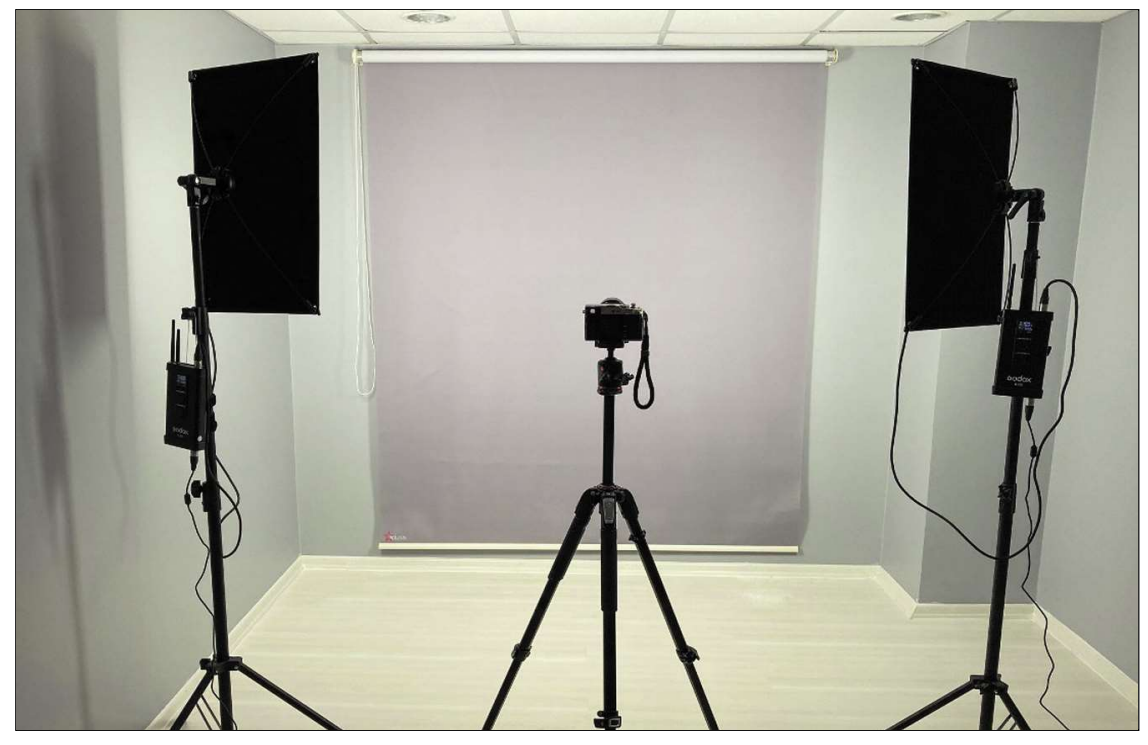

photography equipment for the highest quality images. For high-level facilities we recommend a room with a painted, plain, dark colored wall without any windows to obtain the most accurate color tone as studio setting. A simple example of a medical photography studio is shown in Fig. 1. For low-level facilities, we recommend a special area for photography just at the examination room.

Ratios are the first main step in standardization. To obtain the exact ratios of the photograph, the distance between the camera and the patient must be standard. We recommend a 1 to 2 -meter distance between the patient and the sensor of the camera. We also recommend around 50 centimeters distance between the patient and the background to minimize the shadow of the patient falling on the background $(1,5)$. Thus, the sensor should be positioned between 1.5 and 2.5 meters from the plain backdrop and a simple mark on the floor of the studio to showthe standard position could be used. For framing, the area between the sternal notch and the umbilicus is the best for breast photography. We recommend showing both breasts in the frames that the healthy breast and the pathological breast are shown together, to make the comparison better.

Technical equipment is also very important for standardization. For high-level facilities, aprofessional camera with a changeable lens and with an exposure control system is the best choice. Lens focal length is another important issue. $24-105 \mathrm{~mm}$ (full-frame equivalent) focal length lenses must be chosen. Of note, $50 \mathrm{~mm}$ (full-frame equivalent) is especially useful and, in our opinion, the best focal length for studio clinical photography because $50 \mathrm{~mm}$ focal length has a similar view angle as the human eye. A stable tripod must be used to minimize the vibration in posing during photography.For exposure settings aperture priority mode is the best because the object is steady. Automatic exposure settings are not recommended because standardization might be a problem according to the change during the camera's sensing of the environment. In aperture priority mode, only the aperture is set and the camera controls the shutter speed and the ISO.A large depth of field is better for capturing all of the important anatomic and functional detail of the subject. So, a suitable aperture would be between $\mathrm{f} / 4.5-\mathrm{f} / 5.6$. Spot metering is best for measuring the light in the studio settings. In addition, to prevent image quality reduction, keep the ISO under 400 and around 100 -200 for best results (1-6). For low ${ }^{-}$ level facilities, a standard camera or a mobile phone might be recommended.

Viewpoint is the second issue for standardization. For a continuous follow-up series, viewpoint standardization is the most important 

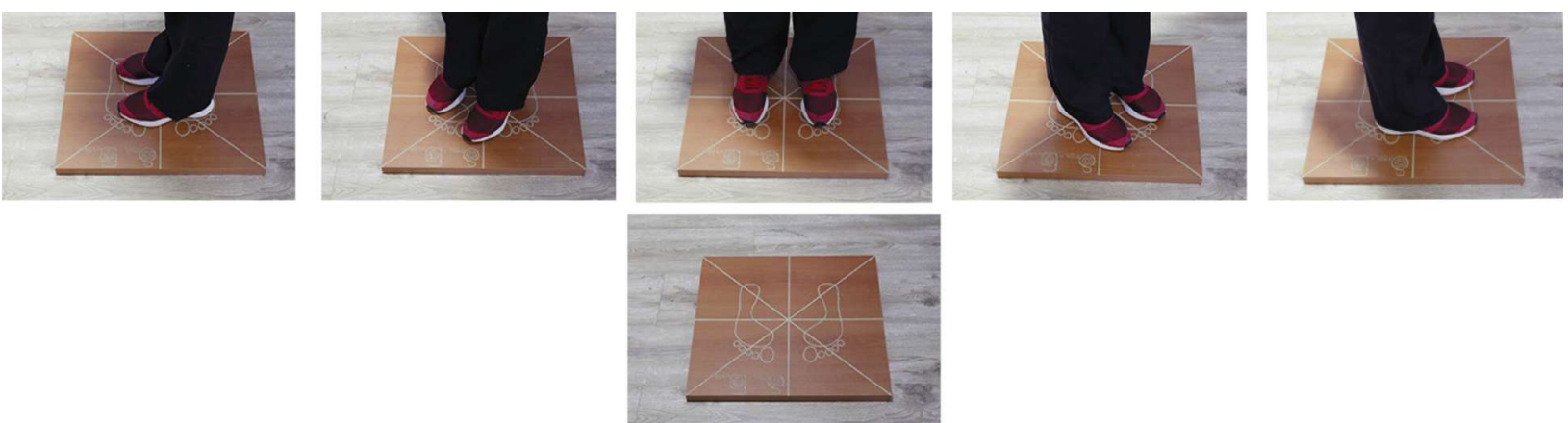

Figure 2. Sample medical photography studio (Kocaeli University Faculty of Medicine, Medical Visual Documentation Unit, Medical Photography Studio, Kocaeli, Turkey) (From the archives of Sertaç Ata Güler)

step. For this reason, a series of ten photographs is recommended which should include anterior, oblique at 45 degrees both sides, lateral both sides with hands-on-hips and anterior, oblique at 45 degrees both sides, lateral both sides with hands-on head. To make it easy we created a standing board forthe patient to simplify posing during the process (Fig. 2). The final result is composed, and a 10-photographseries of images is prepared (Fig. 3). Also, if necessary, specific views of flap donor sites can be taken $(1,5)$.

The background is the third issue. For high-level facilities, a uniform or solid color backdrop is preferable forthe studio setting. Anti-reflected and light to medium blue or $18 \%$ gray are the best colors for the background for a good contrast with skin color $(1,3,5)$. For low-level facilities, one-color wall or fabric curtain or surgical towels attached to the wall is also an option.

A major factor during photography is the light. The type and color of light sources will affect the final images obtained. So appropriate light sources are very important in clinical photography for obtaining the most accurate color tone. For high-level facilities, two matched lights at 45 degrees towards the subject, especially para flashes or led lights are advised. Led sources may give optimal final light as this technology has advanced rapidly in recent years. Extra filling light from reflectors is also helpful. For low-level facilities, standard room lights just over the object is recommended. To minimize the shadow effects of light directly coming from one direction, avoid the use of camera flashes or pop-up integrated flashes that are automatically activated in "P Mode" (1,3,5,7). White balance is also very important to obtain the correct color tone. For this, we recommend experimenting withthe different white balance settings of your camera to achieve the most accurate color tone which is as near to the true
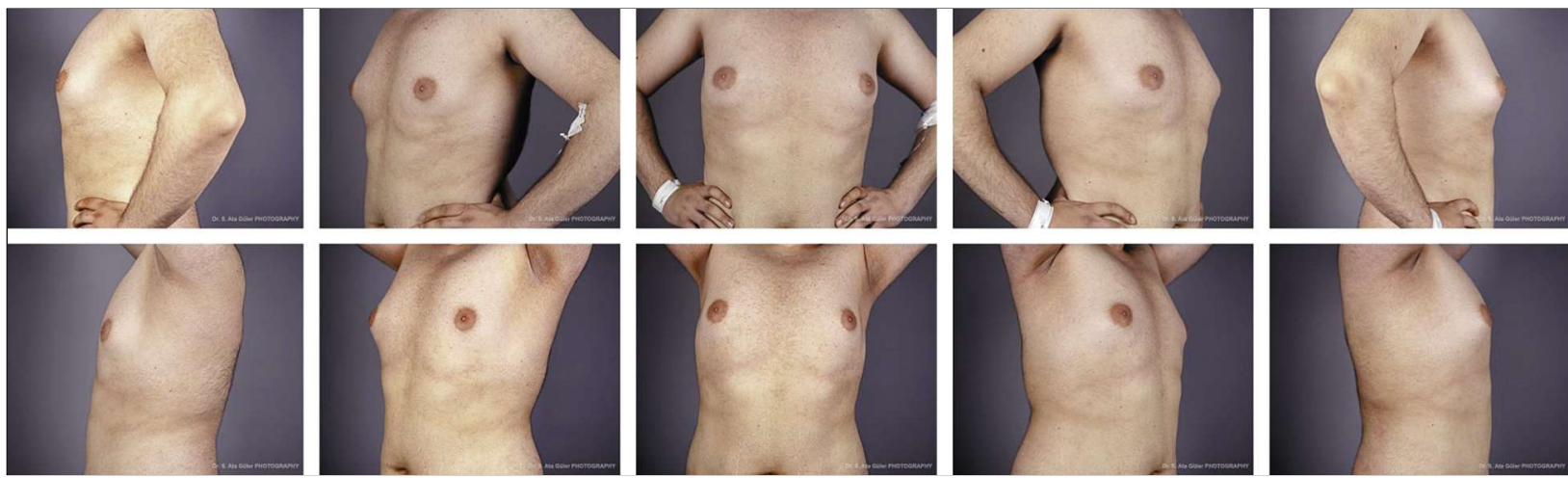

Figure 3. Standardized 10 image series for clinical breast surgery photography (From the archives of Sertaç Ata Güler) 
color tone perceived by the eye (7). For most clinical photography we recommend setting the camera to the custom Kelvin value or the same Kelvin value as the lights of the studio if known. If the Kelvin value of the lights is adjustable, 5600 Kelvin is the optimal setting for achieving the color tone nearest to that of the human eye.

For education of the medical staff who will take the photographs at high-level facilitieswe recommend attending to the medical photography certification programs or courses that various universities organize. Also, for the medical staff of low facilities we recommend at least having the basic photography knowledge to obtain optimum medical visual documents.

For follow-up of disease or cosmes is standardized photography series must be taken for the best results. To standardize the follow-up of breast surgery patients, photographs should be obtained at fixed time points. For follow-up of surgery, effects of radiotherapy, and overall follow-up, recommended periods for photography are given in Table 3 (5).

\section{Intra-operative photography}

This is the subgroup of breast surgery photography when it is used to describe and record the surgery, the steps of the surgery, or the surgical techniques (3). The major difficulty of this type of photography is that it is much less amenable to standardization. The camera and the operating room $(\mathrm{OR})$ settings must be used to form a makeshift studio environment. For the highest quality of intra-operative photography, we recommend obeying the normal sterility demands of the OR and background and light rules as previously described $(1,4)$.

Table 3. Timetable for the photography of breast surgery patients

Follow-up For Surgery Results:

Baseline photography of the breast just before the surgery

Comparative photography of the breast just after surgery

Surgical routine follow-up photography of the breast at postoperative $4^{\text {th }}$ week

Follow-up For Radiotherapy Results:

Baseline photography of the breast just before the radiotherapy

Routine follow-up photography of the breast at $1^{\text {st }}$ and $3^{\text {rd }}$ years

after radiotherapy

Follow-up For Overall Results:

Follow-up photography of the breast at the $1^{\text {st }}, 5^{\text {th }}$, and $10^{\text {th }}$ years
In this type of medical photography, the studio is the OR which must be sterile. So, the first rule must be to obey normal sterility rules. The photographer must approach the sterile area of the operation table and the patient with great care not to compromise sterility. Some camera connection accessories might be useful for taking the perfect images because of the sterilization obstacles. Also, cameras with movable screens rather than using the viewfinder of the camera are recommended for seeing the composition better (1).

The background is a big problem. During surgery, there might be a lot of surgical equipment, bloody sponges, or gauzes in the operation area. These unwanted objects may distract from the composition. So, masking the unwanted objects with sterile unused surgical clothes may give a cleaner background and produce a better-quality medical photograph. Also, just focusing on the object instead of other areas may give the best results (1).

Light may be a further problem. Operation lights are very bright and powerful sources. Control of the light is important for the best exposure. We recommend to not use the operation lights. So, turn them off or change the direction of their beams, if possible. Perhaps extra portable light sources can be used or simply use the normal room lights.

Focusing is a very important to correctly highlight the main subject of the surgery. With the correct combination of light, background, and focusing, the highest-quality intraoperative images can be obtained (Fig. 4).

\section{Specimen photography}

The last subtype of breast photography is specimen photography. The place of the process may change but taking the specimen to the medical photography studio may not be practical. Therefore, simple specimen photography in the operation room is recommended. For specimen photography, we recommend the optimal equipment, background, and light below.

For this kind of photography, a macro lens with a $50 \mathrm{~mm}$ or $60 \mathrm{~mm}$ focal length (fullframe equivalent) gives the best results. In our 


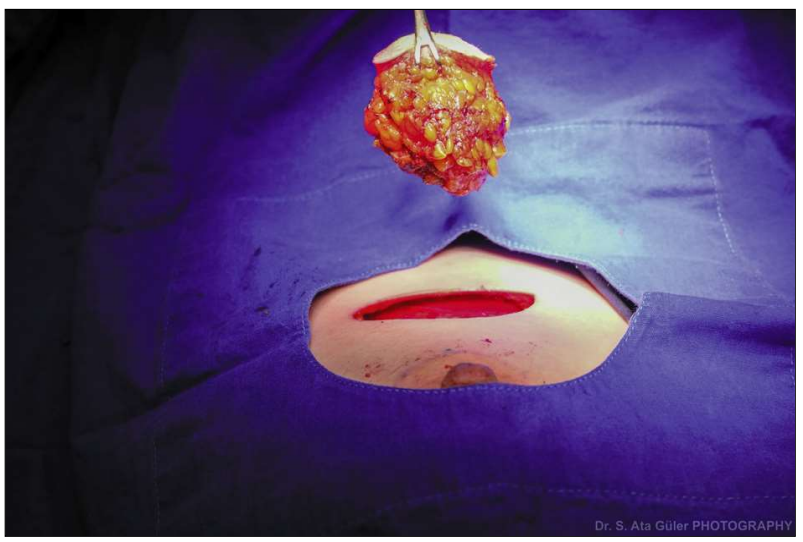

Figure 4. Background, light, and focus combination on intraoperative breast surgery photography

(From the archives of Sertaç Ata Güler)

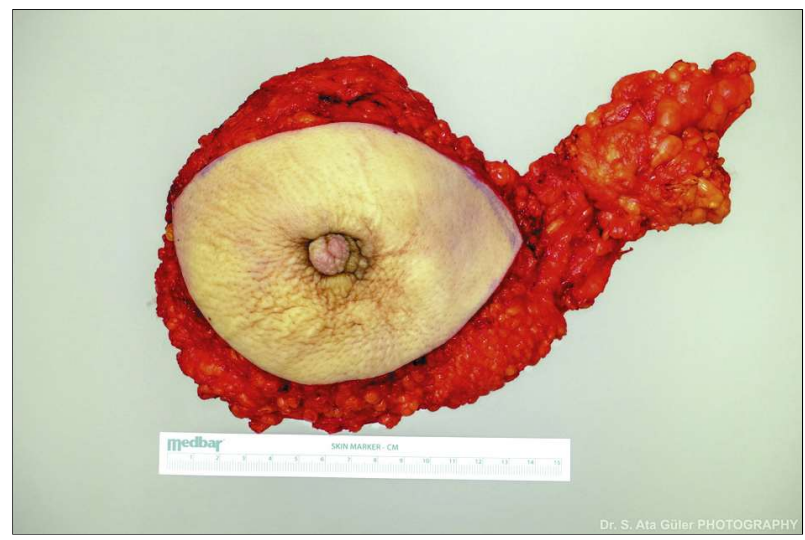

Figure 5. Frosted glass background for specimen breast surgery photography

(From the archives of Sertaç Ata Güler) opinion a macro lens with a focal length of 60 $\mathrm{mm}$ gives the best result. Using a ruler to show the exact dimensions of the specimen is also recommended (1). Also, to make the camera stable, we recommend using a tripod capable of turning through 90 degrees.

The normal background for specimen photography is surgical clothes but a frosted glass standing on four bottles gives better results in our experience (Fig. 5) (1).

Light is also very important in macro photography. So, using a ring flash system or using two light sources on both sides of the specimen to decrease shadows might be recommended.

A combination of intra-operative photography and specimen photography might better record all the steps of the procedure, including dissecting the suspicious area, finding the target lesion, taking it out, and photographing the target lesionsaccording to the rules of specimen photography (Fig. b).

\section{Documentation}

This is an important consideration inmedical photography. After taking the images, the problem of how to collect them, group them, and easily recover them when needed arises.

The most important problem is security. Medical photographs are confidential records. So, using a personal harddisk is recommended instead of cloud storage systems. To avoid losing the data or accidental deletion, two or more backups are recommended periodically to different harddisks (4).

Some photo-editing applications or programs might be helpful for organizing, editing, or backing up medical photos easily. Online medical data management
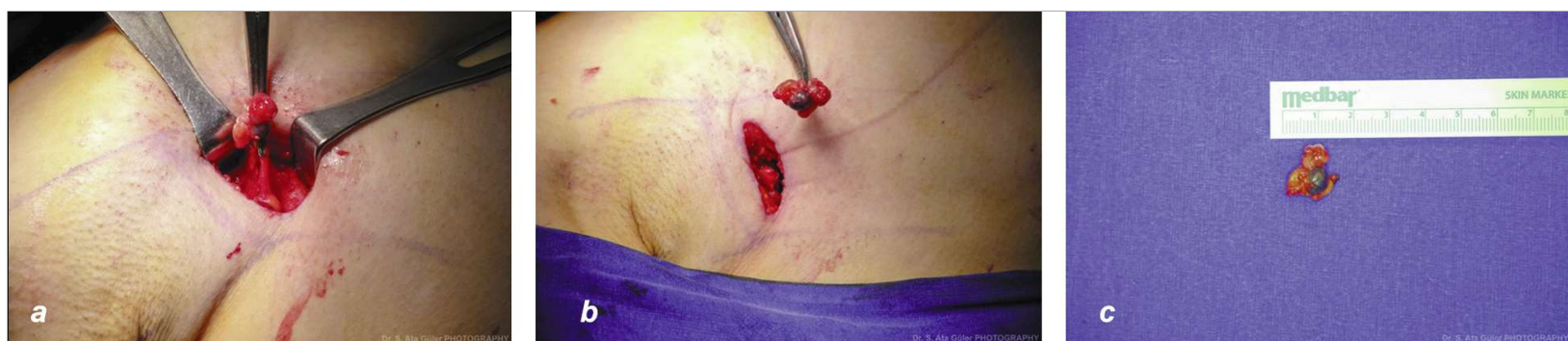

Figure 6. Storytelling with breast surgery; a combination of intra-operative and specimen breast surgery photography: (A) during dissection, (B) just after taking the specimen, (C) specimen (From the archives of Sertaç Ata Güler) 
software using secure servers are available with limited accesswhich might be used for storing medical photographs (4).

\section{Conclusion}

Medical visual documentation is very helpful in breast surgery. To obtain high quality and academically effective images, some recommendations have been made for better medical photography. A full consent process must be followed with each patient for takingclinical, intra-operativeorspecimen photographs.

Additional consent may be required for using those documents in teaching or in academic publications. A standard set of views under standardized conditions should be acquired in a studio setting for each patient. Images must be obtained by following ethical and medical rules and all digital images must be stored on a secure server with limited access.

\section{Acknowledgments}

We thank to Jeremy Jones for revising the English language of the paper, Bahadır M. Gülloğlu for his help about revising the concept and Turgay Şimşek for his help in technical support.

\section{Conflict of Interest}

The authors declare no conflicts of interests.

\section{Ethics Approval}

This is a review article. There is no ethics approval.

\section{References}

1. Guler SA, Akca T. Medical Photography: Historical Development and Basic Concepts. Turk J Dermatol 2017;11:98-108.

2. Sheridan P. Practical aspects of clinical photography: part 1-principles, equipment and technique. ANZ J Surg. 2013;83(3):188-191.

3. Wang K, Kowalski EJ, Chung KC. The art and science of photography in hand surgery. J Hand Surg Am. 2014;39(3):580-588.

4. Sheridan P. Practical aspects of clinical photography: Part 2 - Data management, ethics and quality control. ANZ J Surg. 2013;83(4): 293-95.

5. Cardoso MJ, Cardoso JS, Vrieling C, Macmillan D, Rainsbury D, Heil J, et al. Recommendations for the aesthetic evaluation of breast cancer conservative treatment. Breast Cancer Res Treat. 2012;135(3):629-37.

6. Eadie C, Herd A, Stallard S. An investigation into digital imaging in assessing cosmetic outcome after breast surgery. J Audiov Media Med. 2000;23(1):12-16.

7. Galdino GM, Vogel JE, Vander Kolk CA. Standardizing digital photography: it's not all in the eye of the beholder. Plast Reconstr Surg. 2001;108(5): 1334-1344. 